Notes

[Chem. Pharm. Bull.

35(10)4294-4301(1987)

\title{
Facile Conversions of Carboxylic Acids into Amides, Esters, and Thioesters Using 1,1'-Oxalyldiimidazole and 1,1'-Oxalyldi(1,2,4-triazole $)^{1)}$
}

\author{
Tokujiro Kitagawa, ${ }^{*}$ Hiroko Kuroda, Hideaki Sasaki, \\ and KOICHI KAWASAKI
}

Faculty of Pharmaceutical Sciences, Kobe Gakuin University, Ikawadani, Nishi-ku, Köbe 673, Japan

(Received March 23, 1987)

\begin{abstract}
Aliphatic, aromatic, and heteroaromatic carboxylic acids react with 1,1'-oxalyldiimidazole (1) or 1,1'-oxalyldi(1,2,4-triazole) (2) in acetonitrile for $40 \mathrm{~min}$ at $40^{\circ} \mathrm{C}$ to give the corresponding 1acylazole intermediates (11), which promptly undergo aminolysis and alcoholysis to form amides (13) including dipeptides (14), esters (16), and thioesters (19). These findings show that both 1 and 2 can be utilized as condensing reagents for the synthesis of carboxylic acid derivatives.
\end{abstract}

Keywords_-1,1'-oxalyldiimidazole; 1,1'-oxalyldi(1,2,4-triazole); 1,1'-carbonyldiimidazole; 1-acylazole; condensing reagent; amidation; esterification; dipeptide; aminolysis; alcoholysis

The development of efficient and convenient reagents for functional group conversions is still a major goal in synthetic organic chemistry, and it is also desirable that such conversions for the construction of target molecules should proceed smoothly under mild conditions. In the course of synthetic studies on dehydrating reagents, we have demonstrated that $1,1^{\prime}$ oxalyldiimidazole (1) can be used for the conversion of aldehyde oximes (4) into the corresponding nitriles (5) under neutral conditions, ${ }^{2)}$ and dehydration utilizing 1 also serves as a convenient method for the synthesis of carboxylic acid anhydrides (7). ${ }^{3)}$ Murata has separately shown that the reaction of aliphatic carboxylic acid derivatives such as lithium or sodium linolate with methanol using 1 takes place in chloroform to give the corresponding methyl ester (9) in $79 \%$ yield. ${ }^{4)}$

As indicated in the literature, ${ }^{2,4)}$ the key compounds, 1 and 2 are easily prepared on a laboratory scale by the reaction of 1-(trimethylsilyl)imidazole ${ }^{5)}$ and 1-(trimethylsilyl)-(1,2,4triazole $)^{5)}$ with oxalyl chloride in benzene at room temperature. ${ }^{6)}$ Incidentally, $1,1^{\prime}$ carbonyldiimidazole (Staab's reagent; 3) ${ }^{7)}$ which is structurally analogous to 1 , is frequently used as a condensing or dehydrating reagent for the preparations of amides $(\mathbf{1 3}),{ }^{8}$ dipeptides (14), ${ }^{9)}$ esters (16), ${ }^{10)}$ nitriles (5), ${ }^{11)}$ and acid anhydrides (7). ${ }^{12)}$ Staab's reagent (3), though commercially available, is too expensive for application on a large scale. Furthermore, toxic phosgene, used as a starting material for the preparation of $\mathbf{3}$, requires very careful handling. To overcome these shortcomings in the synthesis of amides (13) and esters (16 or 19), we examined the possibility that substitution of $\mathbf{1}$ or $\mathbf{2}$ for $\mathbf{3}$ as a condensing reagent may be effective for amidations or esterifications.

We now wish to report that compounds 1 and $\mathbf{2}$ are generally useful for the transformation of carboxylic acids (6) into amides (13) including peptides (14), esters (16), and thioesters (19) under mild conditions. The condensation reactions described herein were carried out basically as a two-step, one-pot procedure, as shown in Chart 2; step 1, formation 


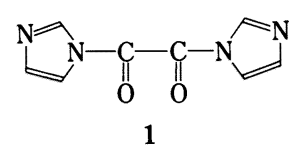<smiles>O=C(C(=O)n1cncn1)n1cncn1</smiles><smiles>O=C(n1ccnc1)n1ccnc1</smiles>

$$
\begin{array}{ccc}
\mathrm{R} \cdot \mathrm{CH}=\mathrm{N} \cdot \mathrm{OH} & \mathbf{1} & \mathrm{R} \cdot \mathrm{C} \equiv \mathrm{N} \\
\mathbf{4} & -\mathrm{H}_{2} \mathrm{O} & 5 \\
\mathrm{R} \cdot \mathrm{COOH} & \frac{1}{6} & -\mathrm{R} \cdot \mathrm{CO})_{2} \mathrm{O} \\
\mathbf{6} & & 7
\end{array}
$$

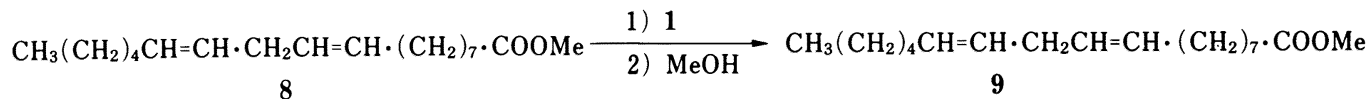
Met : Li or $\mathrm{Na}$

Chart 1

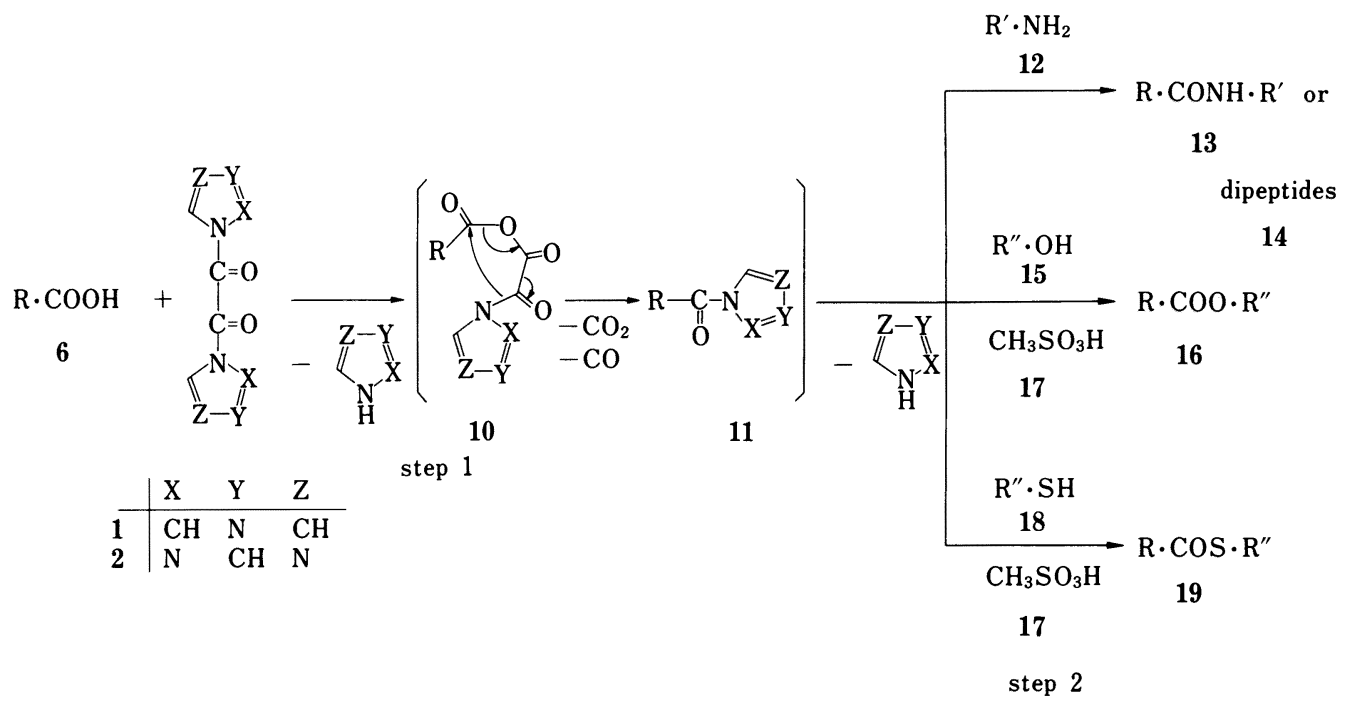

Chart 2

of active 1-acylazoles (11) from the reaction of carboxylic acids (6) with 1 or 2 for 40 min at $40^{\circ} \mathrm{C}$ accompanied with liberation of carbon dioxide and carbon monoxide, and step 2, the 1acylazoles (11) react with amines (12) or alcohols (15 or 18) as nucleophiles to afford amides (13), esters (16) or thioesters (19) as the final products.

\section{Syntheses of Amides (13) and Dipeptides (14)}

First of all, an attempt to prepare benzanilide $(\mathbf{1 3} \mathbf{g})$ from the condensation of benzoic acid and aniline using 1 was very successful (91\% yield). Similarly, other aromatic and heteroaromatic carboxylic acids (6) were also derived as expected into the corresponding amides (13) in acceptable yields. Moreover, we found (Table I) that hindered carboxylic acids 
TABLE I. Preparation of Amides (13) Using 1,1'-Oxalyldiazoles (1 and 2) $\mathrm{R} \cdot \mathrm{CO} \cdot \mathrm{NH} \cdot \mathrm{R}^{\prime}$

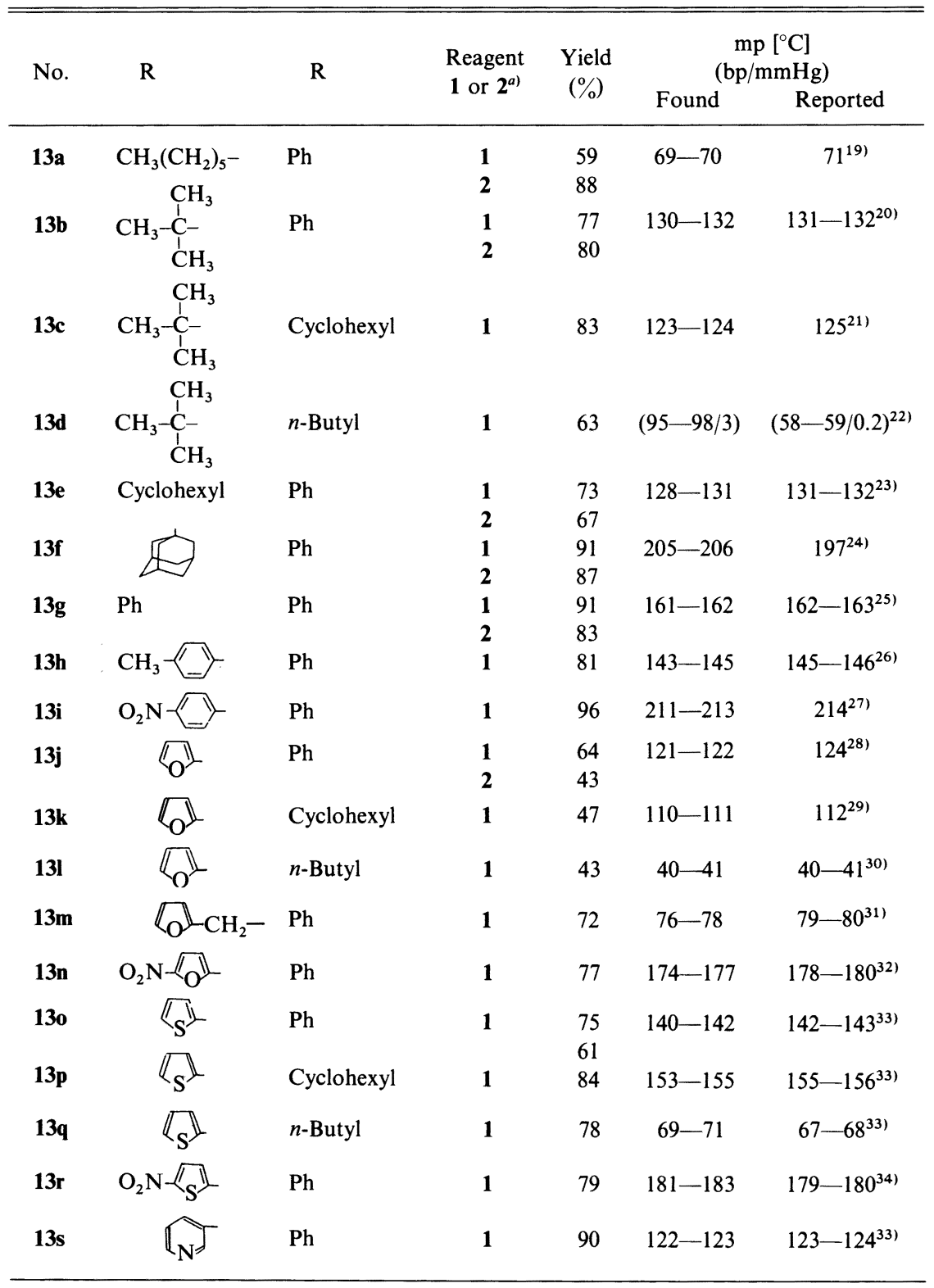

a) Compounds, 13a $-\mathbf{b}, \mathbf{1 3} \mathrm{e}-\mathbf{f}$, and $\mathbf{1 3} \mathbf{j}$, which were prepared using 1,1'-oxalyldi(1,2,4-triazole) (2), were characterized by comparison of their $\mathrm{mp}(\mathrm{bp})$ and IR data with those of authentic samples.

such as 2,2-dimethylpropanoic acid readily react with aniline using 1 to give the corresponding anilide in good yields (13b in $77 \%$ yield in the case mentioned).

Judging from the yields of amides (13) in Table I, it is clear that reagent $\mathbf{1}$ as well as $\mathbf{2}$ is capable of achieving amide formation through the reaction of carboxylic acids (6) with amines (12).

Next, the successful application of $\mathbf{1}$ and $\mathbf{2}$ as condensing reagents led us to investigate their usefulness in peptide bond formation. A typical dipeptide synthesis was started by 


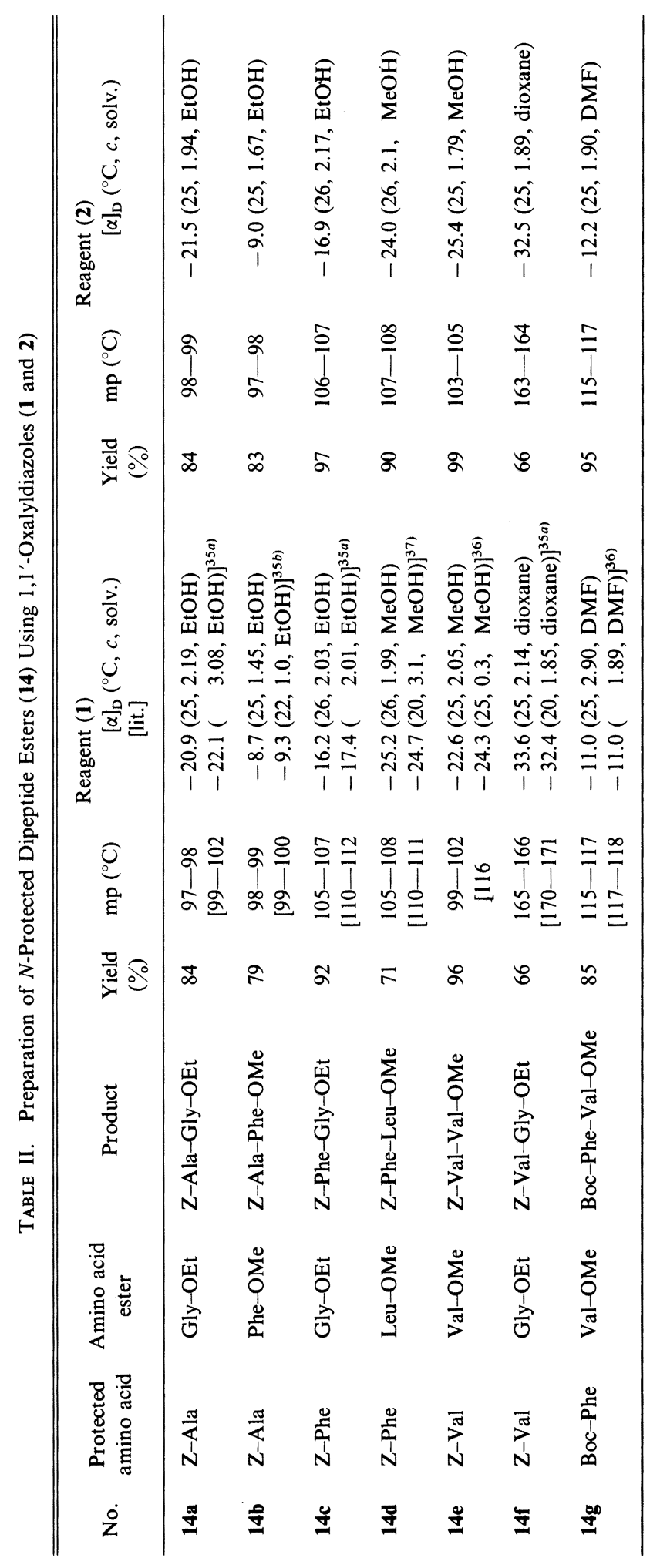


TABle III. Preparation of Esters (14) and Thioesters (18) Using 1,1'-Oxalyldiazoles (1 and 2)

$\mathrm{R} \cdot \underset{\mathrm{O}}{\mathrm{C}} \cdot \mathrm{X} \cdot \mathrm{R}^{\prime \prime}$

\begin{tabular}{|c|c|c|c|c|c|c|c|}
\hline \multirow[t]{2}{*}{ No. } & \multirow[t]{2}{*}{$\mathrm{R}$} & \multirow[t]{2}{*}{$\mathrm{X}$} & \multirow[t]{2}{*}{$\mathrm{R}^{\prime \prime}$} & \multirow{2}{*}{$\begin{array}{l}\text { Reagent } \\
1 \text { or } 2^{a)}\end{array}$} & \multirow{2}{*}{$\begin{array}{l}\text { Yield } \\
(\%)\end{array}$} & \multicolumn{2}{|c|}{$\begin{array}{c}\mathrm{mp}\left[{ }^{\circ} \mathrm{C}\right] \\
(\mathrm{bp} / \mathrm{mmHg})\end{array}$} \\
\hline & & & & & & Found & Reported \\
\hline \multirow[t]{2}{*}{$16 a$} & $\mathrm{CH}_{3}\left(\mathrm{CH}_{2}\right)_{5}-$ & $\mathrm{O}$ & $\mathrm{Me}$ & 1 & 61 & $(82-85 / 30)$ & $(170-173)^{38)}$ \\
\hline & & & & 2 & 72 & & \\
\hline \multirow[t]{2}{*}{$16 \mathrm{~b}$} & Cyclohexyl & $\mathrm{O}$ & $\mathrm{Me}$ & 1 & 65 & $(78-81 / 22)$ & $(181-182)^{39)}$ \\
\hline & & & & 2 & 60 & & \\
\hline \multirow[t]{2}{*}{$16 c$} & & $\mathrm{O}$ & $\mathrm{Me}$ & 1 & 73 & $36-37$ & $38-39^{40)}$ \\
\hline & & & & 2 & 68 & & \\
\hline \multirow[t]{2}{*}{ 16d } & $\mathrm{Ph}$ & $\mathrm{O}$ & $\mathrm{Me}$ & 1 & 67 & $(90-94 / 20)$ & $(195-199)^{41)}$ \\
\hline & & & & 2 & 61 & & \\
\hline \multirow[t]{2}{*}{$19 a$} & $\mathrm{Ph}$ & $\mathrm{S}$ & $\mathrm{Ph}$ & 1 & 78 & $59-60$ & $56-57^{42)}$ \\
\hline & & & & 2 & 75 & & \\
\hline \multirow[t]{2}{*}{$19 b$} & $\mathrm{Ph}$ & $\mathrm{S}$ & & 1 & 63 & $49-50$ & $50-51^{431}$ \\
\hline & & & & 2 & 70 & & \\
\hline \multirow[t]{2}{*}{$16 e$} & & $\mathrm{O}$ & $\mathrm{Me}$ & 1 & 83 & $90-92$ & $96^{44)}$ \\
\hline & & & & 2 & 76 & & \\
\hline \multirow[t]{2}{*}{$19 c$} & & $\mathrm{~S}$ & $\mathrm{Ph}$ & 1 & 54 & $158-160$ & $160-161^{45)}$ \\
\hline & & & & 2 & 66 & & \\
\hline \multirow[t]{2}{*}{$16 f$} & & $\mathrm{O}$ & $\mathrm{Me}$ & 1 & 74 & $(71-74 / 13)$ & $(181.3)^{46)}$ \\
\hline & & & & 2 & 53 & & \\
\hline \multirow[t]{2}{*}{$16 \mathrm{~g}$} & $\mathrm{O}_{2} \mathrm{~N}$ & $\mathrm{O}$ & $\mathrm{Me}$ & 1 & 69 & $78-79$ & $81^{47)}$ \\
\hline & & & & 2 & 73 & & \\
\hline \multirow[t]{2}{*}{$16 \mathrm{~h}$} & & $\mathrm{O}$ & $\mathrm{Me}$ & 1 & 76 & $(90-93 / 11)$ & $(40 / 0.5)^{48)}$ \\
\hline & & & & 2 & 68 & & \\
\hline \multirow[t]{2}{*}{$16 i$} & $\mathrm{O}_{2} \mathrm{~N}$ & $\mathrm{O}$ & $\mathrm{Me}$ & 1 & 80 & $74-76$ & $75^{49)}$ \\
\hline & & & & 2 & 74 & & \\
\hline
\end{tabular}

a) Compounds $16 \mathbf{a}-\mathbf{i}$ and $19 \mathbf{a}-\mathbf{c}$, which were prepared using 1,1'-oxalyldi(1,2,4-triazole) (2), were characterized by comparison of their $\mathrm{mp}(\mathrm{bp})$ and IR data with those of authentic samples.

treating an $N$-protected amino acid with 1 or 2 in acetonitrile for $40 \mathrm{~min}$ at room temperature. Effervescent was immediately observed. An appropriate amino acid ester was reacted for $2 \mathrm{~h}$ at, or slightly above, room temperature to give the corresponding dipeptide (14) in a yield comparable to those obtained by using known condensing reagents, e.g., Staab's reagent (3) ${ }^{13)}$ Racemization was not detectable by nuclear magnetic resonance (NMR) analysis as described in the literature. ${ }^{14)}$

\section{Syntheses of Esters (16) and Thioesters (19)}

The procedure demonstrated in our laboratory was extended to the synthesis of esters (16) and thioesters (19). According to the literature, ${ }^{10 a)}$ esterification of carboxylic acids (6) using Staab's reagent (3) usually requires a base or active halide as a catalyst. For example, it has been reported that sodium or potassium tert-butoxide, ${ }^{15)} 1,8$-diazabicyclo[5,4,0]undec-7ene (DBU), ${ }^{10 b)} \mathrm{N}$-bromosuccinimide (NBS), ${ }^{16)}$ and active halides ${ }^{17)}$ such as allyl bromide, methyl iodide, or benzyl bromide can effect the alcoholysis of 1-acylimidazole (11) derived from the reaction of the carboxylic acid (6) with Staab's reagent (3). Some nitro compounds such as 5-nitro-2-furoic acid or 5-nitro-2-thenoic acid, however, showed great instability when allowed to stand in contact with a basic catalyst such as an alkali metal tert-butoxide or DBU. Thus, it seemed desirable to examine whether acidic catalysts, as well as basic or neutral ones, 
also effect the alcoholysis of 1-acylazoles (11). Hence, we employed methanesulfonic acid (17) as an acidic catalyst. ${ }^{18)}$ To get a better picture of the course of the esterification, the reaction of benzoic acid with 1 in acetonitrile was carried out for $40 \mathrm{~min}$ at $40^{\circ} \mathrm{C}$ to provide 1 benzoylimidazole, which was subsequently reacted with methanol for $2 \mathrm{~h}$ at $60^{\circ} \mathrm{C}$ in the presence of 17 to afford methyl benzoate (16d) in $67 \%$ yield. Next, one of the heteroaromatic nitro compounds in question, 5-nitro-2-furoic acid, was directly converted to the desired methyl ester (16g) in $69 \%$ yield. On the other hand, 2-mercaptopyridine or thiophenol can be used in place of methanol as a nucleophile for the thioesterification. The results of representative cases are summarized in Table III. As judged from the yields (Table III) of reactions so far examined, 2 appears to give similar results to $\mathbf{1}$.

A speculative explanation for the major role of $\mathbf{1 7}$ is as follows. The formation of 1 acylazole methanesulfonates from the reaction of 1-acylazoles (11) with 17 is essential to enhance the leaving ability of the azole ring from 11, so that concerted nucleophilic attack of the alcohol on the carbonyl carbon atom of $\mathbf{1 1}$ can occur readily to form the corresponding esters (16), as shown in Chart 3.

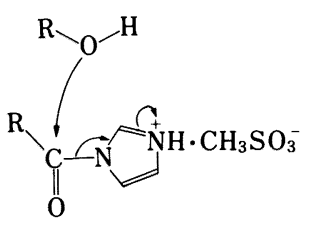

Chart 3

In conclusion, compounds 1 and 2 can be conveniently used as condensing reagents for the direct conversion of carboxylic acid (6) into amides (13) including dipeptides (14), esters (16), and thioesters (19) under mild reaction conditions.

\section{Experimental}

Melting points were taken on a Yanagimoto melting point apparatus. All melting and boiling points are uncorrected. NMR spectra were measured on a Bruker AM-400 spectrometer $(400 \mathrm{MHz})$ using tetramethylsilane as an internal reference, and chemical shifts were recorded as $\delta$-values. Optical rotations were measured on a JASCO DIP-180 polarimeter (Japan Spectroscopic Co., Ltd.). Reagents 1 and 2 were prepared by the known procedures. ${ }^{6)} \mathrm{N}$ Protected amino acids and amino acid ester hydrochlorides were commercial products, and were used without further purification.

Synthesis of Amides (13) - General Procedure Using 1 as a Condensing Reagent: 1 (2.09 g, $11 \mathrm{mmol})$ was added rapidly in a single portion to a stirred solution of the carboxylic acid (6) $(10 \mathrm{mmol})$ in acetonitrile $(30 \mathrm{ml})$. The mexture was stirred at room temperature for $15 \mathrm{~min}$, heated for $40 \mathrm{~min}$ at $40^{\circ} \mathrm{C}$, and then cooled to room temperature. The amine (12) $(10 \mathrm{mmol})$ was added, and the whole was heated again for $2 \mathrm{~h}$ at $60^{\circ} \mathrm{C}$. The solvent was removed in vacuo, the resulting residue was poured into ice-water, and the mixture was extracted with ethyl acetate. The extract was washed with $5 \% \mathrm{NaHCO}_{3}, 2 \% \mathrm{HCl}$, and water, then dried over anhydrous $\mathrm{Na}_{2} \mathrm{SO}_{4}$. The organic solvent was evaporated off in vacuo to give the crude amide (13), which was purified by distillation or recrystallization.

Synthesis of $\mathbf{N}$-Protected Dipeptide Esters (14)—_-General Procedure Using 1 as a Condensing Reagent: A wellstirred solution of $N$-protected $\alpha$-amino acid $(10 \mathrm{mmol})$ in acetonitrile $(30 \mathrm{ml})$ was cooled to $10^{\circ} \mathrm{C}$ and treated with 1 $(2.09 \mathrm{~g}, 11 \mathrm{mmol})$ while maintaining the reaction temperature at below $15^{\circ} \mathrm{C}$. Stirring was continued for $1 \mathrm{~h}$ at $15-$ $20^{\circ} \mathrm{C}$, then a mixture of $\alpha$-amino acid ester hydrochloride $(10 \mathrm{mmol})$ and triethylamine $(10 \mathrm{mmol})$ in acetonitrile $(5 \mathrm{ml})$ was added. The resultant mixture was stirred for $2 \mathrm{~h}$ at $10-15^{\circ} \mathrm{C}$. After removal of the solvent in vacuo, the residue was dissolved in ethyl acetate and the organic solution was washed with $5 \% \mathrm{NaHCO}_{3} 2 \% \mathrm{HCl}$, and saturated brine, then dried over anhydrous $\mathrm{Na}_{2} \mathrm{SO}_{4}$. The organic solvent was evaporated off in vacuo to give the crude dipeptide, which was purified by recrystallization.

Synthesis of Esters (16 and 19)_-General Procedure Using 1 as Condensing Reagent:1 (2.09 g, $11 \mathrm{mmol})$ was added rapidly in a single portion to a stirred solution of carboxylic acid $(10 \mathrm{mmol})$ in acetonitrile $(20 \mathrm{ml})$. The mixture was stirred for $15 \mathrm{~min}$ at room temperature, heated for $40 \mathrm{~min}$ at $40^{\circ} \mathrm{C}$, then cooled to room temperature. A solution of methanol $(10 \mathrm{mmol})$ or the thiol $(18)(10 \mathrm{mmol})$ and $17(2.1 \mathrm{~g}, 20 \mathrm{mmol})$ in acetonitrile $(10 \mathrm{ml})$ was added dropwise. The resultant mixture was heated for $2 \mathrm{~h}$ at $60^{\circ} \mathrm{C}$. After removal of the solvent in vacuo, the resulting residue was poured into ice-water, and the mixture was extracted with ethyl acetate. The extract was washed with $5 \% \mathrm{NaHCO}_{3}$ 
and water, and then dried over anhydrous $\mathrm{Na}_{2} \mathrm{SO}_{4}$. The organic solvent was evaporated off in vacuo to give the crude ester (16) or thioester (19), which was purified by distillation or recrystallization.

Acknowledgment This work was supported in part by a Grant-in Aid for Scientific Research (No. 61226013) from the Ministry of Education, Science and Culture, Japan. The authors with to thank Misses M. Imura, Y. Itakura, T. Iida, Y. Takeuchi, and K. Gushi for their technical assistance in a part of this work. The authors are also indebted to BASF Japan for providing many intermediates.

\section{References and Notes}

1) Parts of this work were presented at the 35th local meeting of the Pharmaceutical Society of Japan at Kyoto, November 2, 1985. Abstracts p. 36.

2) T. Kitagawa, H. Sasaki, and N. Ono, Chem. Pharm. Bull., 33, 4014 (1985).

3) T. Kitagawa, H. Kuroda, and H. Sasaki, Chem. Pharm. Bull., 35, 1262 (1987).

4) a) S. Murata, Chem. Lett., 1983, 1819; b) Idem, Bull. Chem. Soc. Jpn., 57, 3597 (1984).

5) L. Brikofer, P. Richter, and A. Ritter, Chem. Ber., 93, 2804 (1960).

6) W. Walter and M. Radke, Justus Liebigs Ann. Chem., 1979, 1756.

7) a) H. A. Staab, Angew. Chem. Int. Ed. Engl., 1, 351 (1962); b) S. Ohta and M. Okamoto, Yuki Gosei Kagaku Kyokai Shi, 41, 38 (1983) [Chem. Abstr., 98, 124969r (1983)].

8) H. A. Staab and K. Wendel, Chem. Ber., 93, 2910 (1960).

9) a) R. Paul and G. W. Anderson, J. Org. Chem., 27, 2094 (1962); b) H. A. Staab, Justus Liebigs Ann. Chem., 609, 75 (1959).

10) a) von H-J. Gais, Angew. Chem., 89, 251 (1977); b) T. Kamijio, H. Harada, and K. Iizuka, Chem. Pharm. Bull., 32, 5044 (1984); c) S. Ohta, A. Shimabayashi, M. Aono, and M. Okamoto, Synthesis, 1983, 833.

11) a) T. Kamijio, H. Harada, and K. Iizuka, Chem. Pharm. Bull., 32, 2560 (1984); b) H. G. Foley and D. R. Dalton, J. Chem. Soc., Chem. Commun., 1973, 628.

12) H. A. Staab, G. Walther, and W. Rohr, Chem. Ber., 95, 2073 (1962).

13) a) G. W. Anderson and R. Paul, J. Am. Chem. Soc., 80, 4423 (1958); b) R. Paul and G. W. Anderson, J. Am. Chem. Soc., 82, 4596 (1960).

14) For instance, in the NMR spectrum of $\mathrm{Z}$-Ala-Phe-OMe (14b), the methyl signal of the alanyl group appeared as a doublet $(J=7 \mathrm{~Hz})$ centered at $\delta 1.32$, which is similar to the $\delta$ value (1.30) of Z-L-Ala-L-Phe-OMe reported by Weinstein et al. Conversely, in the case of Z-D-Ala-L-Phe-OMe, the corresponding methyl signal appeared as a doublet at higher field $(\delta 1.27) . a)$ B. Weinstein and A. E. Pritchard, J. Chem. Soc., Perkin Trans. 1, 1972, $1015 ; b)$ B. Halpern, L. F. Chew, and B. Weinstein, J. Am. Chem. Soc., 89, 5051 (1967); c) K. Kawasaki, S. Okusada, and T. Tsuji, "Peptide Chemistry 1984," ed. by N. Izumiya, Protein Research Foundation, Osaka, 1985 , p. 71.

15) H. A. Staab and A. Mannschreck, Chem. Ber., 95, 1284 (1962); see also ref. $4 a$.

16) T. Katsuki, Bull. Chem. Soc. Jpn., 49, 2019 (1976).

17) T. Kamijio, R. Yamamoto, H. Harada, and K. Iizuka, Chem. Pharm. Bull., 30, 4242 (1982); see also ref. $10 a$.

18) Methanesulfonic acid (17) was first used for activation of 3 in the dehydration of $\alpha$-formylamino acid into the corresponding isocyanide by Ugi and his co-workers. G. Giesemann, E. von Hinrichs, and I. Ugi, J. Chem. Res. $(S), 1982,79$.

19) J. S. Lumsden, J. Chem. Soc., 87, 90 (1905).

20) H. E. Ungnade, J. Am. Chem. Soc., 67, 5133 (1954).

21) G. T. Tisue, S. Linke, and W. Lwowski, J. Am. Chem. Soc., 89, 6303 (1967).

22) A. Pelter, T. E. Levitt, and P. Nelson, Tetrahedron, 26, 1539 (1970).

23) E. K. Harvill, R. M. Herbst, E. C. Schreiner, and C. W. Roberts, J. Org. Chem., 15, 662 (1950).

24) H. Stetter and E. Rauscher, Chem. Ber., 93, 1161 (1960).

25) R. Mestres and C. Palomo, Synthesis, 1982, 288.

26) P. Krishnamurti, Chem. Zentralbl., 1929 I, 2156 [Chem. Abstr., 23, 2164 (1929)].

27) O. L. Brady and R. P. Mehta, J. Chem. Soc., 125, 2297 (1924).

28) L. Vargha and F. Gönczy, J. Am. Chem. Soc., 72, 2738 (1950).

29) C. V. Bowen and L. E. Smith, J. Am. Chem. Soc., 62, 3522 (1940).

30) W. M. Degnan and F. B. Pope, J. Am. Chem. Soc., 62, 1960 (1940).

31) M. M. Runde, E. W. Scott, and J. R. Johnson, J. Am. Chem. Soc., 52, 1284 (1930).

32) H. R. Snyder, Jr., J. Med. Chem., 10, 737 (1967).

33) T. Kametani, T. Takano, O. Umezawa, H. Agui, K. Kanno, Y. Konno, S. Satoh, H. Nemoto, and K. Yamaki, Yakugaku Zasshi, 86, 823 (1966) [Chem. Abstr., 65, $20093 \mathrm{~g}$ (1966)].

34) M. Bellenghi, G. Carrara, F. Fava, E. Ginoulhiac, C. Martinuzzi, A. Vecchi, and G. Weitnauer, Gazz. Chim. Ital., 82, 773 (1952) [Chem. Abstr., 48, 2029i (1954)]. 
35) a) M. Furukawa, N. Hokama, and T. Okawara, Synthesis, 1983, 42; b) E. Schröder, Justus Liebigs Ann. Chem., 679, 207 (1964).

36) M. Ueda, H. Oikawa, N. Kawaharasaki, and Y. Imai, Bull. Chem. Soc. Jpn., 56, 2485 (1983).

37) M. Ueda and H. Oikawa, J. Org. Chem., 50, 760 (1985).

38) A. I. Vogel, J. Chem. Soc., 1948, 624.

39) S. S. Nametkin and M. A. Volodira, J. Gen. Chem. USSR, 17, 325 (1947) [Chem. Abstr., 42, 527g (1948)].

40) H. Koch and W. Haaf, "Organic Syntheses," Vol. 44, ed. by W. E. Parham, John Wiley and Sons, Inc., New. York, 1964, p. 1.

41) G. Graebe, Justus Liebigs Ann. Chem., 340, 244 (1905).

42) Y. Kanaoka, K. Tanizawa, E. Sato, O. Yonemitsu, and Y. Ban, Chem. Pharm. Bull., 15, 593 (1967).

43) M. Araki, S. Sakata, H. Takei, and T. Mukaiyama, Bull. Chem. Soc. Jpn., 47, 1777 (1974).

44) K. Alder, He. Söll, and Ha. Söll, Justus Liebigs Ann. Chem., 565, 73 (1949).

45) A. Takamizawa, Y. Sato, and S. Tanaka, Yakugaku Zasshi, 85, 298 (1965) [Chem. Abstr., 63, 9940h (1965)].

46) K. Auwers, Chem. Ber., 44, 3679 (1911).

47) S. Nishida, T. Sato, and Y. Sato, Repts. Sci. Research Inst. (Japan), 31, 430 (1955) [Chem. Abstr., 50, 15504a (1956)]

48) B. Weinstein, J. Am. Chem. Soc., 77, 6709 (1955).

49) P. Fournari and J. P. Chane, Bull. Soc. Chim. Fr., 1963, 479 [Chem. Abstr., 59, 1569e (1963)]. 